\title{
Assessment of geoecological conditions and the depletion risk of the river Belaya catchment area
}

\author{
Elvira Nafikova $^{1 *}$, Alexey Elizaryev ${ }^{1,2}$, Ayaz Ismagilov ${ }^{1}$, Inna $_{\text {Dorosh }}{ }^{1}$, Aidar Khaidarshin $^{1}$, \\ and Dmitriy Alexandrov ${ }^{1}$ \\ ${ }^{1}$ Ufa State Aviation Technical University, Karla Marksa, 12, Ufa, 450000, Russia \\ ${ }^{2}$ Water Problems Institute of RAS, Gubkina, 3, Moscow,119333, Russia
}

\begin{abstract}
At the present time water resources in the Republic of Bashkortostan (Russia) are exposed by negative anthropogenic influence. Natural processes also contribute to the depletion of water resources. The implementation of the water management system raises a number of methodological problems: the uncertainty of the criteria for assessing the ecological status of water bodies; the complexity of the relationship between the quantitative and qualitative characteristics of the water body due to the regional natural, anthropogenic, climatic features of the territory. The aim of this study is to development of a method for calculating the risk of water resources depletion. The method was tested on the river Belaya (Republic of Bashkortostan, Russia) catchment area. In calculating of water resources depletion risk several parameters were taken into account in particular: the area of watershed, catchment data of surface water and groundwater, data of land use, the average annual runoff, karst phenomena, vegetation. In this paper we use the method of import of geo data containing the soil composition, vegetation, geological structure and forest to assess the ecological condition of the river Belaya. There are defined the catchment areas of the river Belaya, which required immediate management solutions. Mapping of the Belaya River catchment areas requiring immediate management decisions was carried out.
\end{abstract}

\section{Introduction}

Assessment of the ecological state of water bodies is an essential element of environmental management. At the present time water resources in the Republic of Bashkortostan are exposed by negative anthropogenic influence. With the development of agriculture and industry, as well as the urban growth the water intake for irrigation and water supply is continuously increasing. Water consumption is a major cause of environmental problems related to the hydrosphere. Increasing of freshwater use for agriculture, industry, energy and municipal economy causes its deficiency and disturbs the balance between the consumption of clean water and purified water returning to biosphere. It leads to the depletion of water resources and the threat of fresh water shortage. Wastewater formed

\footnotetext{
*Corresponding author: vira2006@yandex.ru
} 
after manufacturing processes generally is not treated effectively, and consequently such water cannot be used for closed water cycle.

Natural processes also contribute to the depletion of water resources and as such geological phenomena - karst processes associated with the dissolution of the water rocks (limestone, dolomite, gypsum, rock salt), thereby forming underground cavities (caves, caverns, etc.) accompanied by the failure of the surface of the earth. Karst is widespread in the world, including Russia, in particular, the Republic of Bashkortostan, in the central part of the Russian Plain, in the Angara region, the North Caucasus and in many other places, where there are soluble rocks. The economic use of areas with karst rock masses leads to a significant change in the environment. In this case karst processes are accelerated considerably: the formation of new washouts, funnels, wells and others. Intensive groundwater intake and dynamic vibration effects of transport and constructions, static load and other factors (possible groundwater contamination) significantly enhance these processes.

There are known works that separately evaluate the disturbance of functions of geosystems [1], evaluating only the quality of water resources [2-10], changes in the mode and quantity of the main components of water resources - surface water and groundwater [11], extreme hydrological phenomena of water availability (floods, shortage of water) [12].

The implementation of the water management system raises a number of methodological problems: the uncertainty of the criteria for assessing the ecological status of water bodies; the complexity of the relationship between the quantitative and qualitative characteristics of the water body due to the regional natural, anthropogenic, climatic features of the territory.

Therefore, the geo-ecological assessment of the state of water flow must take into account both quantitative and the qualitative components of depletion.

\section{The case study}

The catchment area of the river Belaya is $141900 \mathrm{~km}^{2}$. On the river banks there are many large cities of the Republic of Bashkirtostan: Beloretsk, Meleuz, Salavat, Ishimbay, Sterlitamak, Ufa, Birsk, Dyurtyuli, Agidel. The river begins in the east of mountain Iremel. Upper reaches of the river begin in a low, swampy valley. After the village of Tirlyan the river valley narrows sharply, in some parts the river bank is steep, precipitous and covered by forest. After the confluence of the river Nugush, as entering the plain, the valley is gradually expanded, and after the confluence of the river Ufa, the Belaya becomes a typically lowland river. Flowing over a vast floodplain, the river is divided into several branches. Right bank is more exalted. The hydrological regime is dominated by snow melting. The average discharge of water in the estuary is $950 \mathrm{~m}^{3} / \mathrm{s}$. The largest inflows are Nugush, Sim, Ufa, Bir, Bystryj Tanyp, Ashkadar, Dema, Urshak, Baza. The Ufa is the one of the most important waterway of the Republic of Bashkortostan. The river is navigable, inhabited by mostly small fish - minnows, pikes, perches. The water intake is accompanied by the pollution of the river. The main pollutants of the river Belaya are chlorides, sulfates, phosphorus, oil, mercury compounds. The main cause of water pollution is the lack of the capacity of wastewater treatment plants. As a result of unsustainable human activities there is a gradual depletion of water resources.

The largest irrevocable water consumer is agriculture. Irrigation and livestock farming withdraw large amounts of water for food production. It is estimated that the production of the daily norm of food products per person requires at least $6 \mathrm{~m}^{3}$ of water, part of which is consumed irrecoverably, and the other part is contaminated with chemicals, dissolving them, and returned in this form to the biosphere. Industry is also contributes significantly to 
the irrevocable water consumption. In the industrial production water is used as a coolant, absorber, solvent and as a means of transporting.

For nuclear and thermal power plants, heating systems of urban settlements, water is used as the coolant. It transports heat energy (power station, boiler, etc.) to a place of consumption. The use of water as a solvent is carried out mainly in the petrochemical, chemical industries, agriculture (dissolution of chemical compounds for plant nutrition and pest control). In the chemical industry, construction industry and other sectors of economy, water is used for manufacturing of new synthetic substances and materials as a part of the final product. In some cases, water is used as the absorber (washing, cleaning of products and raw materials etc.). Thus, mechanical impurities and soluble chemicals pollute it. Housing and communal services of cities address the needs of residents in the water for drinking, food, hygienic needs. Besides that, the service consume water for its own needs by several organizations: boiler rooms, bath and laundry facilities, buildings of water-sports and recreational activities.

From there the water flows already polluted by surfactants (detergents), organic, bacterial and biological impurities. In cities and villages water is used in irrigation systems of green areas according to Russian water-resources inventory. The zone of fresh hydrocarbon groundwater occupies the upper part of the geological section. Capacity aquifer varies from $10 \mathrm{~m}$ in the river valleys up to $200 \mathrm{~m}$ in the watershed, reaching $400 \mathrm{~m}$ in the Lower Permian sediments of the Bashkir vault and 600 meters in Upper Permian trough Belsky depression. Groundwater represents $46.17 \%$ of the total water consumption of fresh water in the republic. Not all areas of the Republic of Bashkortostan meet the needs of the population for clean water. For example, in the western regions, such as Tuymazinsky, Bizhbulyaksky, Belebeevsky, Ermekeevsky, groundwater contamination is observed over large areas due to economic activity. The contamination of groundwater occurs under the influence of anthropogenic factors in the geological environment, violates the geo-ecological balance. In general, the water resources of the river Belaya are rich and quite sufficient for normal water supply. However, their distribution in the seasons of the year is extremely uneven.

Thus, in the western regions the spring runoff is on average $70 \%$ of the total annual runoff. So, most of the water flows in the rivers during the spring flood. In summer, when the water is mostly needed for water supply and irrigation, it is in deficit, especially in smaller rivers. To align the runoff in the river Belaya large reservoirs and ponds have been built.

\section{The water resources depletion risk analysis and calculation}

Calculation of the geoecological risk of depletion and pollution of water courses is based on determining the long-term (chronic) impact (water pollution, depletion of water resources, the degradation of the river network), developed by the International Institute for health risk assessment. A basin approach was used to assess the risk of depletion of the Belaya River (Bashkortostan, Russia) as the Belaya River also flows beyond the territory of the Republic of Bashkortostan.

As the initial data the following was used:

- GIS data on boundaries of watersheds and waterways;

- soil maps;

- vegetation data;

- data on the types of geological structures;

- land use data;

- data on catchments of surface and ground water;

- average annual water discharge; 
- data on average annual level of precipitation;

- data on the hydrochemical water quality of rivers [13-15].

According to the available data of daily hydrological characteristics in the studied crosssections the average annual runoff for the period of the years 1990-2017 is performed.

The study period is selected on the basis of the completeness of the initial information.

On the basis of the available data of daily hydrological characteristics the average annual runoff was calculated in the studied gauges for the period of $1990-2017$. The study period is selected by the completeness of the initial information. Also, the catchment zoning of the river Belaya was performed, which allows to differentiate the territory according to the geological structure. Karsts are presented with the eluvium of limestone and other calcareous rocks, calcareous loess-like deposits and losses occupying totally $22 \%$ of the river Belaya catchment. These sedimentary rocks increase the risk of the depletion of water resources.

When calculating the risk of the quantitative depletion of water resources, it has been proposed to take into account the land use and types of the soil cover.

For this purpose an information map - the schemes of the land use and the soil types of the river Belaya catchment were designed (Figure 1, Figure 2).

It was found that the majority of the catchment area is occupied by arable land (agricultural land), vegetation and deciduous forest. In areas of large industrial centers the catchment area is almost completely "sealed".
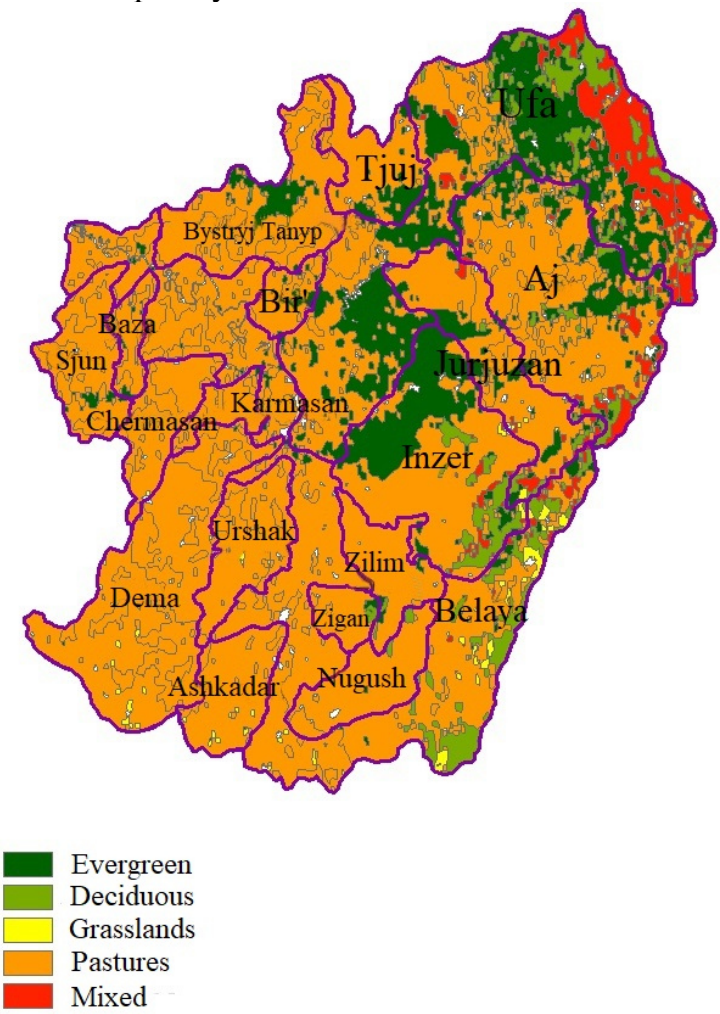

Fig. 1. Map-visual scheme of the land use of the river Belaya catchment 


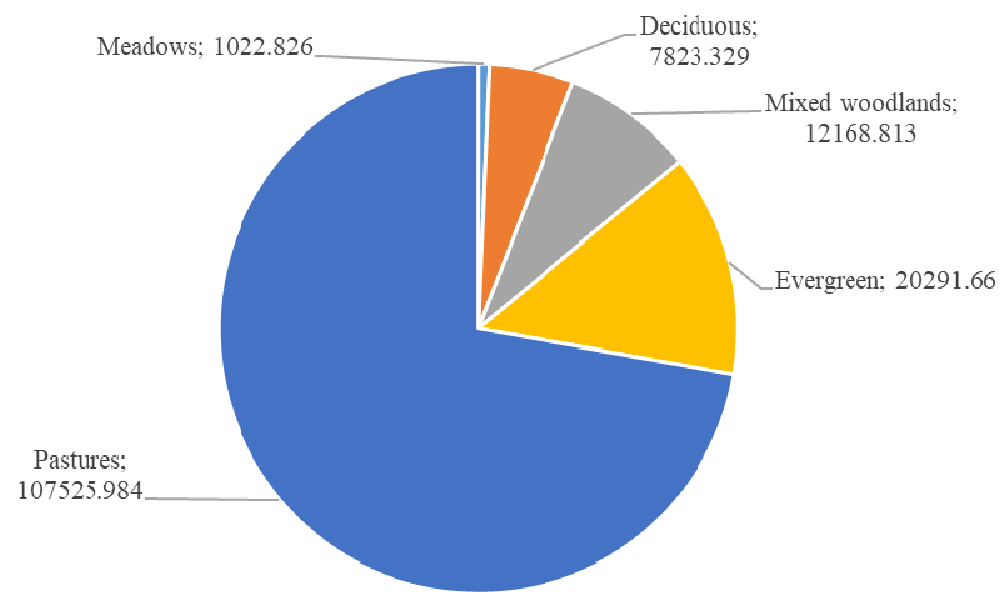

Fig. 2. Diagram-distribution of the occupied area by land use types of the Belaya River catchment

In the software product ArcGIS 10.1 have been calculated the areas of each type of land use (figure 1) and the type of soil cover (figure 3) for each catchment by using standard methods of ArcGIS 10.1 software package.

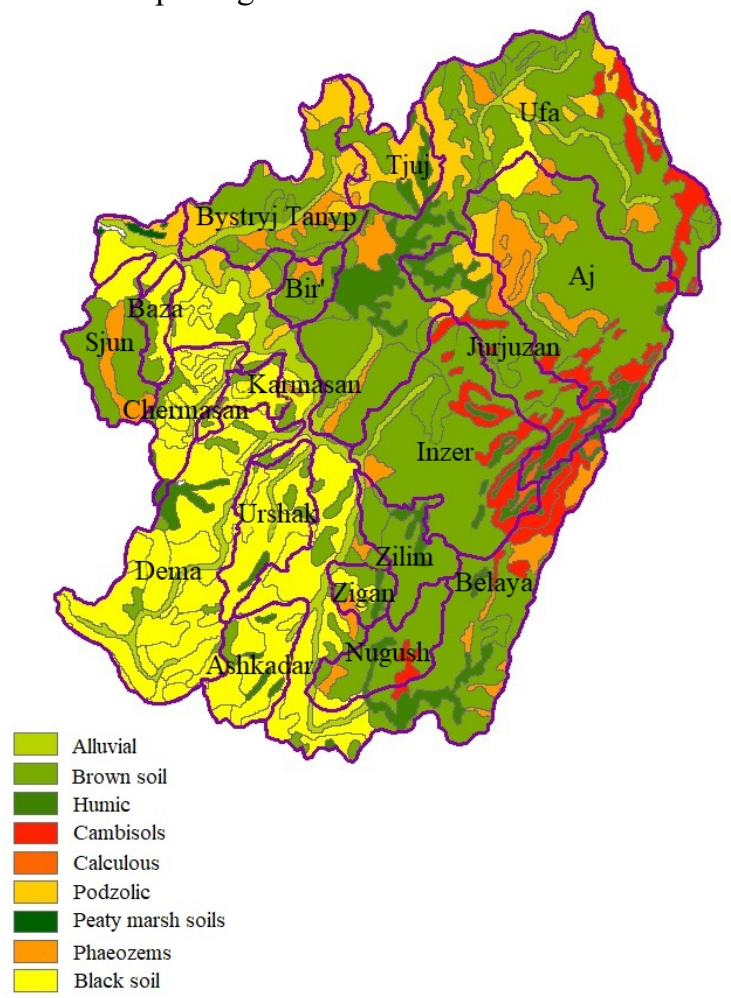

Fig. 3. Map - the scheme of soils of the river Belaya catchment

To calculate the water resources depletion risk many parameters must be taken into consideration. Therefore, to simplify the calculations alongside with the following input and adjustment of the initial data, all geographic and account information about the river Belaya is integrated into a common geographic database. 
The resulting spatial data combining baseline information was the basis for the calculation of risk of depletion of the water resources of the river Belaya.

The magnitude of the risk factor and the depletion of water resources were calculated according to the formulas:

$$
\operatorname{Risk}_{\mathrm{dpl}}=1-\exp \{\ell \mathrm{n}(0.84) \cdot \mathrm{Kdpl} \cdot \mathrm{Kc}\}
$$

where $K_{d p l}$ - factor depletion of water resources;

$K c$ - correction factor depending on the variation of the depletion factor $\left(K_{d p l}\right):(0.1,0.5$, 0.5 - 1.0, 1.0 - 1.5, 1.5 - 2.0, 2.0 - 2.5 > 2.5). $K c(0.5,1.0,1.5,2.0,2.5,3.0)$.

$K_{d p l}$ - depletion factor is calculated as follows:

$$
\mathrm{K}_{\mathrm{dpl}}=\left(\mathrm{V}_{\mathrm{s}}+\mathrm{V}_{\mathrm{u}}\right) /\left(\mathrm{Q} \cdot \mathrm{S} \cdot \mathrm{K}_{\mathrm{use}}\right)
$$

where $\mathrm{V}_{\mathrm{s}}$ - water intake of surface waters, $\cdot 10^{3} \mathrm{~m}^{3} / \mathrm{km}^{2}$.

$\mathrm{V}_{\mathrm{s}}$ - water intake of underground waters, $\cdot 10^{3} \mathrm{~m}^{3} / \mathrm{km}^{2}$.

Q- average annual runoff, $\mathrm{m}^{3} / \mathrm{s}$;

$\mathrm{S}$ - catchment area, $\mathrm{km}^{2}$;

$\mathrm{K}_{\mathrm{use}}$ - correction factor depending on the type of soil and land use.

$\mathrm{K}_{\mathrm{str}}$ - correction factor of the geological structure of the drainage basin surface

$\mathrm{K}_{\mathrm{veg}}$ - correction factor depending on the type of vegetation of floodplain areas

The assessment of the water quality of the river Belaya in terms of the specific combinatorial index of water pollution was carried out for spring, summer and autumn and winter hydrological seasons. The calculation of the combinatorial index of pollution and the relative assessment of water quality was carried out in three stages: first, by each of studied indicators and ingredients of water pollution, then the whole complex of pollutants was considered at the same time and finally the resulting estimate was derived.

The developed model of combining spatial characteristics of the catchment area when working with geographic database allows to obtain express information on the studied characteristics for the given area (such as the type of the land use of the area, the average annual water consumption, the volume of the surface and underground water intake for the current catchment area). It allows to reduce the complexity of the preparation of the initial data for the calculation of the risk of the depletion of water resources.

The resulting spatial combining data have become the basis of water resources depletion risk calculation of the river Belaya.

The water quality complex evaluation system has been used to calculate the specific combinatorial index of water pollution (SCIWP) and to determine the water pollution coefficient of each of the Belaya monitoring posts under study. This system is carefully described in according to Russian RD 52.24.643 - 2002.

The comprehensive assessment of the Belaya water quality is determined by the following indicators: total mineralization, ammonia nitrogen, nitrite nitrogen, nitrate nitrogen, dissolved oxygen, biological oxygen demand, chemical oxygen demand, sulfate, chloride, phenol, petroleum products, total iron, copper, nickel and manganese.

The risk of pollution of the river was determined for study post by the formula:

$\mathrm{K}_{\mathrm{st}}-$ stock coefficient taken equal to 10 ;

$$
\operatorname{Risk}_{\mathrm{p}}=1-\exp \left\{\ln (0,84) \cdot \mathrm{SCIWP} \cdot \mathrm{K}_{\mathrm{p}} \cdot \mathrm{K}_{\mathrm{st}}\right\}
$$

$\mathrm{K}_{\mathrm{p}}$ - pollution coefficient

In formula (3) $K_{p}$ is a correction factor that takes into account the class of water quality of water bodies, and depends on the variations of the values of the specific combinatorial index of water pollution.

The risk of the quantitative and qualitative depletion of the watercourse is a generalized indicator which shows the risk of contamination and risk of the quantitative depletion of water resources. To evaluate the geoecological state of the river Belaya in the studied catchments (from 1990 to 2017), the risk of quantitative and qualitative depletion of water 
resources in the surveyed posts of the river Belaya was calculated using the formula given in the paper:

$$
\text { Risk mid }=1 \exp 1 / 2\left\{\ln \left(1-\operatorname{Risk}_{\mathrm{p}}\right)+\ln \left(1-\mathrm{Risk}_{\mathrm{dpl}}\right)\right\}
$$

The classification of the geoecological risk of depletion and pollution of water resources accepted from :

$0-0.25$ - "weak";

0.25-0.5 - "medium";

0.5-0.75 - "strong";

0.75-1.0 - "very strong."

The largest risk exhaustion and pollution of water resources is shown in Figure 4. The risk of depletion of water resources of the river Belaya RB ranges from 0.73 to 0.9 .

The zoning map of the river Belaya according to the magnitude of depletion and pollution of water resources risk is presented in Figure 4. The risk ranges from 0.73 to 0.9 .

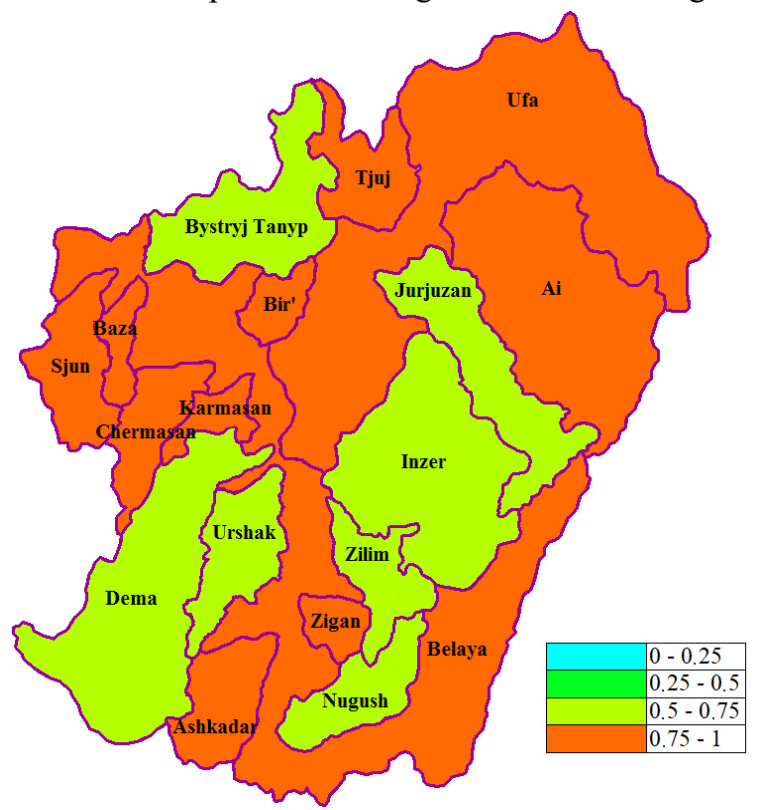

Fig. 4. Map - the scheme of zoning the river Belaya catchments by the degree of the geoecological risk of water depletion and pollution

The results of calculation of the risk of the depletion of water resources showed that the highest water consumption occurs in the main catchment area of the river Belaya, since it is the most full-flowing and provides water to the cities of the Republic of Bashkortostan.

Environmental protection measures can reduce the pollution of rivers.

However, the problem of the protection of water resources cannot be solved until the discharge of untreated and poorly treated water will not be stopped. The only direction in solving the problem of water protection - is the transition to a closed water system, the reduction until the complete cessation of the discharge of untreated water. Having the water resources protection issue it is also important to design the industrial plants, so that they consume less water. 


\section{References}

1. N.V. Angelopoulos, J.P. Harvey, J.D. Bolland, A.D. Nunn, I.G. Cowx. Journal of Environmental Management, 224, 69-76 (2018) (https://doi.org/10.1016/j.jenvman.2018.07.030)

2. X. Wang, J. Li, J. Chen, L. Cui, W. Li, X. Gao, Z. Liu. Chemosphere, 243 (2020) (https://doi.org/10.1016/j.chemosphere.2019.125328)

3. T. Marara, L. G. Palamuleni. Physics and Chemistry of the Earth, Parts A/B/C, 114 (2019) (https://doi.org/10.1016/j.pce.2019.09.001)

4. M. Shamsudduha, D.K. Panda. International Journal of Disaster Risk Reduction, 35 (2019) (https://doi.org/10.1016/j.ijdrr.2019.101068)

5. A. Arenas-Sánchez, A. Rico, D. Rivas-Tabares, A. Blanco, M. Vighi. Science of The Total Environment, $\quad \mathbf{6 6 7}, \quad 222-233 \quad$ (2019) (https://doi.org/10.1016/j.scitotenv.2019.02.286)

6. M.M. Aldaya, E. Custodio, R. Llamas, M.F. Fernández, J. García, M.Á.Ródenas. Science of The Total Environment, 662, 755-768 (2019) (https://doi.org/10.1016/j.scitotenv.2019.01.266)

7. Z. Yang, K. Shah, S. Laforest, B.P. Hollebone, J. Situ, C. Crevier, P. Lambert, C.E. Brown, C. Yang. Environmental Pollution, $258 \quad$ (2020) (https://doi.org/10.1016/j.envpol.2019.113769)

8. D. Jaiswal, J. Pandey. Environmental Research, 178 (2019) (https://doi.org/10.1016/j.envres.2019.108712)

9. M.E. Goher, M.H. Ali, S.M. El-Sayed. The Egyptian Journal of Aquatic Research, 45, 301-312 (2019) (https://doi.org/10.1016/j.ejar.2019.12.002)

10. L. Ngwira, D. Lakudzala. Physics and Chemistry of the Earth, Parts A/B/C, 108, 9-12 (2018) (https://doi.org/10.1016/j.pce.2018.04.002)

11. M.S. Malik, J.P. Shukla. Groundwater for Sustainable Development, 9 (2019) (https://doi.org/10.1016/j.gsd.2019.100249)

12. J. Tang, S. Wang, Y. Tai, N.F. Tam, L. Su, Y. Shi, B. Luo, R. Tao, Y. Yang, X. Zhang. Water Research, 170 (2020) (https://doi.org/10.1016/j.watres.2019.115302)

13. International Union of Geodesy and Geophysics: http://www.iugg.org/

14. Russian River Watershed Geospatial Data Catalog: http://www.russianriverwatershed.net

15. The CGIAR Consortium for Spatial Information (CGIAR-CSI) http://srtm.csi.cgiar.org/ 